\title{
Visualising Immigrant Fertility - Profiles of Childbearing and their Implications for Migration Research
}

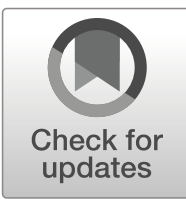

\author{
Marianne Tønnessen ${ }^{1}$ (D) Ben Wilson ${ }^{2,3}$ \\ Published online: 14 July 2020 \\ C) The Author(s) 2020, corrected publication 2020
}

\begin{abstract}
Different measures of fertility have strengths and limitations when used to describe the fertility of immigrants, and no single measure captures every aspect of this complex phenomenon. This paper introduces a novel visual framework that shows life course profiles of immigrant childbearing in a multifaceted way. It develops the well-known cohort fertility curve-showing the average number of children ever born over the life course - and adds lines for immigrant women arriving at different ages, using their average number of children born on arrival as a starting point. These immigrant fertility profiles can illustrate a number of important aspects of childbearing simultaneously, including children born before arrival, fertility after arrival and completed fertility at the end of childbearing. In addition to showing numbers of children born (i.e. fertility quantum), the slopes of each profile indicate the tempo of fertility and how this changes by age and duration of residence. The fertility profiles of different immigrant groups can be plotted in the same graph, and can be compared and contrasted with non-immigrant groups - at origin as well as destination - through the augmentation of each visualisation. Using Nordic register data, we illustrate how these fertility profiles can be used to expand our knowledge of immigrant childbearing and to investigate various hypotheses of migrant fertility, giving a novel overview of the relationships between fertility measures such as period and quantum, before and after arrival.
\end{abstract}

Keywords Migration · Fertility · Immigrant fertility $\cdot$ Fertility measures $\cdot$ Demography

Marianne Tønnessen

mariton@oslomet.no

1 Norwegian Institute for Urban and Regional Research, Oslo Metropolitan University, P.O. Box 4, St. Olavs plass, NO-0130 Oslo, Norway

2 Department of Sociology, Stockholm University, 10691 Stockholm, Sweden

3 Department of Methodology, London School of Economics, Houghton St, London WC2A 2AE, UK 


\section{Introduction}

The fertility of immigrants and their descendants has received considerable attention over the last few decades (Kulu et al. 2019), not least because levels of immigration have risen in many countries, especially in most high-income European destinations (Eurostat 2019a). This trend has led to an increased interest in many aspects of immigrant's lives, including their fertility, which we define here as childbearing behaviour over the reproductive life course. The childbearing of immigrants has long been of interest to academics - in particular demographers - partly due to the impact of immigration on population size and population composition (Haug et al. 2002; Jonsson and Rendall 2004; Sobotka 2008). Researchers have been interested in the determinants of immigrant fertility, including the impact that destinations have on the childbearing of immigrants after arrival (Kulu and González-Ferrer 2014). This has led to a range of hypotheses, some of which make predictions about the profile of (female) immigrant fertility over the reproductive life course (Kulu 2005; Milewski 2010a).

Despite the many potential motivations for studying immigrant fertility, researchers face several important challenges when researching this topic. One important challenge is how to measure immigrant childbearing. There are a range of different ways to measure fertility, irrespective of the population of interest (Preston et al. 2000). However, thanks to the work of a range of scholars over the last few decades, it has become clear that some measures may be less appropriate for studying immigrant fertility, or, at a minimum, that some measures have the potential to be misinterpreted (Hoem and Nedoluzhko 2016; Parrado 2011; Toulemon 2006). For example, there has long been an interest among researchers - and many other segments of society-in whether immigrant women have more children than native-born women (e.g. Adserà and Ferrer 2016; Hill 1913; Murphy 1995; Parrado and Flippen 2012; Yusuf and Rockett 1981), and this question has often been evaluated using the period total fertility rate (period TFR) (e.g. Dubuc 2012; Haug et al. 2002; Sobotka 2008). However, the period TFR has been heavily criticised and shown to give a misleading impression of the difference between immigrants and natives in their average number of births (Parrado 2011; Sobotka and Lutz 2011; Toulemon 2004, 2006; Toulemon and Mazuy 2004).

Different fertility measures have different strengths and weaknesses when it comes to measuring immigrants' fertility. For instance, some strengths of the period TFR are that it is relatively easy to calculate and it can give timely information, but it can give a misleading estimate of differences between immigrants and natives with respect to their number of births, in part because it only captures the fertility behaviour of immigrants after they arrive in the destination (Parrado 2011). By contrast, completed fertility measures all births, including birth to immigrants prior to arrival, but it can only be estimated for women who are close to the end of their reproductive careers (Parrado and Morgan 2008), and it requires data on pre-migration births that can be hard to obtain. As we argue here, the most appropriate choice of fertility measure depends upon the precise motivation for studying immigrant fertility. There is no measure that is always better or best (including the one we propose below). However, most measures that are commonly used provide only a partial view of immigrant's reproductive lives.

Here, we address this gap by proposing an innovative approach that visualises immigrant fertility profiles. The approach builds upon previous research that has 
studied and visualised cohort fertility for national populations (Frejka and Calot 2001a, b). It also builds upon studies that highlight the challenges of measuring immigrant fertility, especially due to the fact that it is typically associated with age at arrival and duration of residence (Hoem and Nedoluzhko 2014, 2016; Toulemon 2004, 2006; Toulemon and Mazuy 2004). In essence, our approach is to plot the cohort fertility of immigrants over their reproductive life course - i.e. their profile of fertility over agewhile also showing their children ever born at arrival. A similar approach has been used elsewhere to show how the childbearing of female immigrants varies over their reproductive lives as compared with the childbearing of native-born women (Wilson 2019). A key advantage of studying immigrant fertility profiles in this way is that they provide insights about both tempo (i.e. birth timing) and quantum (i.e. number of births). Here, we develop this approach and implement a visual method that offers several distinct advantages, not least because it provides a unique overview of the complex dynamics of immigrant fertility, from arrival onwards. This visual approach therefore goes beyond measures of immigrant fertility that are restricted to a specific aspect of the reproductive life course. Moreover, it is a summary measure that is flexible enough to describe the changing fertility profiles of any immigrant population (or subpopulation), including as compared with the non-immigrant destination population (or any reference group, including non-migrants in origin countries).

In the rest of this paper, we demonstrate this approach and its advantages. We believe that the visualisation of fertility profiles can be used as a tool to supplement the use of other measures of fertility, including as a guide to choosing the most suitable measures of immigrant fertility for answering specific research questions, and as a way of informing studies of specific theories and hypotheses. Many hypotheses have been put forward to explain migrant fertility (e.g. see Milewski 2010a), and here we refer to several of those that are most commonly used when studying first-generation immigrants, specifically adaptation, childhood socialisation, selection, disruption and the interrelation of events. We note that there are other explanations for immigrant fertility (e.g. anticipation, legitimacy) and that in any case we do not seek to test these hypotheses. Definitions of each hypothesis can vary, but broadly speaking they can be defined as follows: the adaptation hypothesis predicts that the fertility of immigrants will converge towards a destination norm with increasing duration of residence, the childhood socialisation hypothesis predicts that exposure to fertility norms and preferences during childhood is a determinant of immigrant fertility behaviour, the selection hypothesis predicts that immigrant fertility is determined by the fact that they are different from other women in their origin (and destination), the disruption hypothesis predicts that migration will interrupt childbearing (at least temporarily), and the interrelation of events hypothesis predicts that the impact of migration on fertility is dependent upon the role of other events, in particular partnership.

In the next section, we provide a brief summary of the most common approaches that have been used to measure and analyse immigrant fertility. This is followed by a section that introduces our approach using a stylised plot, which not only illustrates the advantages of visualising immigrant fertility profiles but also helps illuminate issues around the interpretation of immigrant fertility differentials (e.g. comparisons with nonimmigrants) and decisions about how to measure immigrant fertility. The penultimate section then provides a series of empirical examples using Nordic register data. In essence, these examples seek to answer the question: How can we visualise immigrant 
fertility profiles in order to understand the complex dynamics of immigrants' childbearing? We discuss several empirical examples in turn, describing how they offer new insights for those who wish to understand immigrant fertility. The final section then discusses the strengths and limitations of this visual approach and makes recommendations for the literature moving forward.

\section{Different Measures of Immigrant Fertility: Their Strengths and Limitations}

There are a variety of ways to measure fertility. Similarly, there are many potential ways to classify different fertility measures. In this section, we discuss the three most common approaches that have been used to measure and analyse the fertility behaviour of immigrants. ${ }^{1}$ To supplement our discussion, we provide examples in Appendix Table $1 .^{2}$

The first approach is to analyse total fertility rates (TFRs), which are almost always estimated for a specific year or combination of years (i.e. a given period). Period TFRs can be seen as cross-sectional measures of aggregate fertility (or as measures for a synthetic cohort). They measure fertility variation by age, but at one point in the life course for each person (i.e. at a given childbearing age), rather than longitudinally. The second approach concerns measures based on event history analysis, which are typically used to analyse transitions between different parities (sometimes called 'birth intensities'), where parity is defined as the number of children women have previously borne. The third approach is to analyse number of children ever born. This can be measured at a specific age, such as children ever born recorded cross-sectionally for women aged 15-45, or at the end of childbearing, which is often referred to as 'completed fertility'. It can even be measured longitudinally, as in the case of our empirical examples below that focus on longitudinal profiles of cumulative cohort fertility. These measures can be used to estimate fertility profiles for people who have yet to complete their childbearing, but what makes them different is that they focus on cumulative childbearing, as opposed to focusing on a specific segment of the childbearing life course. In the rest of this section, we provide a summary of these approaches, alongside a brief discussion of some of their strengths and limitations.

\section{Total Fertility Rates}

There are many different types of fertility rate, including the crude birth rate, general birth rate, age-specific fertility rates and the TFR. Of these, the most commonly used to

\footnotetext{
${ }^{1}$ Another approach is to analyse non-behavioural measures of childbearing, such as attitudes, intentions, values, preferences or norms (e.g. see Milewski and Mussino 2019). We ignore this approach here given our focus on fertility behaviour.

${ }^{2}$ This table is only illustrative. Some studies have used more than one measure, and some measures are difficult to classify using these four categories. Moreover, the table only refers to some examples from the literature. Given our aims here, a systematic review is beyond the scope of this article, but this means that there are many excellent studies of immigrant fertility that are missing from Appendix Table 1. Nevertheless, this table helps to highlight the fact that the literature on immigrant fertility has not been so focused on measures of fertility profiles.
} 
study immigrant fertility in recent decades has been the period TFR. It is referred to as a period measure of fertility because it is based on the births that occur in a given period, which is often a calendar year. The period TFR is defined as the average number of children that a group of women would have if they experienced the age-specific fertility rates for a particular period across their entire reproductive life course (Hinde 1998; Kuczynski 1932). It is for this reason that the period TFR is often considered to be a synthetic measure, such that it does not consider the behaviour of people longitudinally, but instead imagines what fertility would look like if everyone had the age-specific fertility rates of a given period.

The advantages of a period TFR include the fact that it is easy to calculate. It does not require detailed data on fertility history, either at the individual or the population level. It merely requires cross-sectional information on age-specific fertility rates (ASFRs). Added to this, the period TFR is a timely measure, which provides a summary of contemporary fertility behaviour. These attributes may explain why it has become one of the most frequently used measures for estimating and evaluating migrant fertility differentials, especially by the national statistics agencies who supply official statistics to government, and the policy-makers who seek to evaluate timely statistics on immigrant fertility differentials (Haug et al. 2002; Héran and Pison 2007; Østby 2002; Parrado 2011; Sobotka 2008; Sobotka and Lutz 2011; Tromans et al. 2007; Zumpe et al. 2012).

Despite their potential benefits, there are also disadvantages when using period measures, like the period TFR, to study immigrant fertility. The period TFR is frequently interpreted as the number of children born, for example to compare two populations or subpopulations. However, it is well known that comparisons can be distorted by differences between these populations in their timing of births (Hajnal 1947; Ní Bhrolcháin 1992, 2011). This issue may be particularly problematic for studies of migrant fertility differentials, where the timing of migrant births is known to relate to the timing of migration (Murphy 1995; Singley and Landale 1998; Toulemon and Mazuy 2004; Andersson 2004). If immigrant birth risks are elevated after arrival, as has often been observed, then conclusions may be biased when using period TFRs to estimate differences in fertility quantum between immigrants and nonimmigrant 'natives' (Parrado 2011; Toulemon 2004, 2006; Toulemon and Mazuy 2004). Researchers have proposed alternative measures, or adjusted measures, of period TFRs (Hoem and Mureşan 2011; Kulu et al. 2019; Persson and Hoem 2014; Toulemon 2006), some of which may help to mitigate some of the disadvantages mentioned previously. Nevertheless, when using period TFRs to make inferences about differences in the quantum of fertility, such inferences may be biased by tempo effects.

In summary, the benefits of period TFRs include that they are easy to calculate, provide a summary of contemporary fertility behaviour and place low requirements on data. However, they may not always be the best measure for studying immigrant fertility, especially when the aim is to make inferences about differences between immigrants and non-immigrants in their fertility quantum.

\section{Measures Based on Event History Analysis}

As an alternative to period TFRs, researchers have increasingly turned to event history analysis in order to examine the dynamics of immigrant childbearing. Recent research, 
most notably in Europe, has utilised this approach in order to develop a host of insights about immigrant fertility (see Appendix Table 1, and also Kulu et al. 2019; Kulu and Milewski 2007). Event history approaches are typically used in order to study the timing of births for specific parities (where parity refers to whether a child is the firstborn, second-born etc), ${ }^{3}$ in some cases examining the timing of multiple parities at the same time. ${ }^{4}$ These measures, however, require information on parity (which TFR does not).

One clear advantage of event history approaches is that they are perfectly aligned with questions that relate to birth timing, or the 'intensity' of fertility by parity. Another advantage of event history is that it is easily used to study people longitudinally, even if they have not yet completed their childbearing (e.g. women aged 15-45). In general, event history copes well where some life courses are only partially observed (i.e. some women are 'censored' and may have further births) (Courgeau and Lelievre 1991; Hobcraft and Murphy 1986). ${ }^{5}$ By focusing on different parities, it is arguably much easier to understand the dynamics and determinants of fertility, including via the modelling of multiple covariates. It is also possible to gain an overview by comparing analyses of different parities.

Despite these advantages, there are potential drawbacks to using event history approaches when studying immigrant fertility. Probably the main drawback is the fact that they are not well suited to answering questions about number of children born (i.e. fertility quantum), at least not as they are commonly applied. This is essentially because birth rates that are estimated using event history approaches do not necessarily bring clarity in efforts to distinguish between quantum and tempo. Parity-specific birth rates might be high because births take place relatively quickly or because they take place with an overall high intensity (implying high progression rates to next birth). There are also difficulties with analysing fertility before migration, especially in deciding how to treat people who arrive having already had children. For example, they could be dropped from an analysis of first birth timing, which would sacrifice generalisability, or they could be included, which would mix periods of exposure before and after arrival. In general, the analysis of fertility prior to arrival is methodologically challenging and runs the risk of anticipatory analysis (Hoem and Nedoluzhko 2016).

In summary, the benefits of event history approaches include that they focus on birth timing, they are longitudinal and they distinguish between different birth events. However, they may not always be the best approaches for studying immigrant fertility, especially when the aim is to make inferences about differences between immigrants and non-immigrants with respect to fertility quantum, including differences in quantum before and after arrival.

\footnotetext{
${ }^{3}$ We refer here to the timing of births. We note that the timing of migration (and/or the impact of duration of residence) could be studied using any fertility measure (for examples of published studies, see Ford 1990; Adserà and Ferrer 2016).

${ }^{4}$ Other approaches, such as sequence analysis, can also be used to analyse fertility by parity (Kraus 2019).

5 This does not remove the requirement for assumptions about these incomplete cases. For example, censoring is assumed to be non-informative, and all women are assumed to be (conditionally) homogenous (in terms of time-specific birth probabilities) unless different 'frailties' are considered in the modelling (Mills 2011; Steele 2005; Steele et al. 2007).
} 


\section{Number of Children Ever Born}

Alongside approaches based on TFRs or event history, the other most common approach to measuring and analysing immigrant fertility is to estimate numbers of children ever born. If this is done at the end of the reproductive life course, then it is usually referred to as completed fertility (or completed cohort fertility). However, number of children born can also be estimated for people who have not yet completed their fertility, for example by asking questions in surveys of women who are aged 1545.

One advantage of approaches based on number of children ever born is that they directly measure fertility quantum, which is often the aspect of fertility that researchers are interested in, for example if they are seeking to understand whether immigrants have more children than those who are native-born. This is even more the case with completed fertility, which is unaffected by period or tempo distortions. On its own, however, the analysis of completed fertility does not show how immigrant childbearing varies earlier in the life course. This could be examined using samples that include women who have yet to complete their childbearing, measuring their children ever born only when they are surveyed. However, this is potentially problematic for research on quantum differences between immigrants and the non-immigrant population because of differences in birth timing (e.g. due to disruption or interrelation of events), as well as the age composition of the sample. This issue can be problematic even when age is 'controlled for', irrespective of the statistical methods that are used. Related to this is the fact that analyses of children ever born do not normally distinguish between children born before and after arrival (again, often because data do not enable such a distinction). This makes it difficult to evaluate changes in childbearing behaviour after arrival.

A more reliable way to examine how quantum differentials vary over the life course is to study longitudinal profiles of numbers of children born (i.e. cumulative cohort fertility). There are only a relatively small number of studies that have analysed the longitudinal profiles of cumulative fertility for immigrants-i.e. changes in cumulative cohort fertility over the reproductive life course. As shown in more detail later, such profiles not only demonstrate changes in the quantum of fertility but also changes in tempo. Some studies have analysed the completed and partially completed cumulative fertility profiles of specific cohorts of immigrants (e.g. Alders 2000; Bagavos et al. 2007; Fokkema et al. 2008; Friedlander and Goldscheider 1978; Garssen and Nicolaas 2008). Most of these studies examine fertility profiles by estimating cohort fertility for all immigrants, sometimes by country of birth. However, none of these studies have estimated cohort fertility profiles by age at arrival. This is an important gap in research because age at arrival is related to one of the most important sources of complexity in immigrant fertility research, namely the interdependence between migration and fertility. It is possible, as we will show, to estimate (and plot) cumulative fertility profiles by birth cohort and by age at arrival. Such a measure has the potential to generate numerous insights about the dynamics of immigrant fertility and can also help researchers to understand whether theoretical predictions (like selection) are relevant for the research questions (and data) that they intend to study. 


\section{Visualising Immigrant Fertility Profiles}

In this section, we introduce our approach to visualising fertility profiles. This approach is based on the well-known curve of cumulative cohort fertility, showing children ever born by age: an increasing line where the end point can be interpreted as completed fertility. We make an innovation from the typical usage (which is to plot these curves when studying national populations) by plotting lines for immigrant women arriving at different ages, using their average number of children ever born on arrival as a starting point. This approach illustrates a number of important aspects of fertility simultaneously:

(a) The average number of children ever born to immigrants when they arrive.

(b) Average levels of immigrant fertility quantum after arrival.

(c) The birth tempo of immigrants after arrival (shown by the slope of the line).

(d) The completed fertility of immigrants.

A stylised version is shown in Fig. 1, which displays the aspects listed previously, while also showing how these aspects vary by age at migration and duration of residence. By adding a comparison line for non-immigrant 'natives' in the destination, it is also possible to compare immigrants with natives on all of these aspects. Other comparison lines could also be drawn, for example for the descendants of immigrants.

The grey line in Fig. 1 shows the profile of children ever born for non-immigrant 'native' women. At age 30, the average non-immigrant woman has had one birth, and at age 40 she has had almost two. Immigrant women in group A arrive at age 25 . At this age - i.e. at arrival - they have had fewer births than non-immigrants (as shown by the red dot). However, from this age onward they have a similar tempo of fertility, as shown by the slope of the red line, which has a similar gradient to the grey line. Because of their relatively lower level of fertility on arrival, however, they have lower completed fertility than non-immigrant women (despite having similar tempo after arrival). Group B, on the other hand, have had more births than non-immigrants when they arrive at age 30, but have the same completed fertility due to their lower fertility after arrival. Finally, group $\mathrm{C}$ arrive at age 35 with a high number of pre-migration

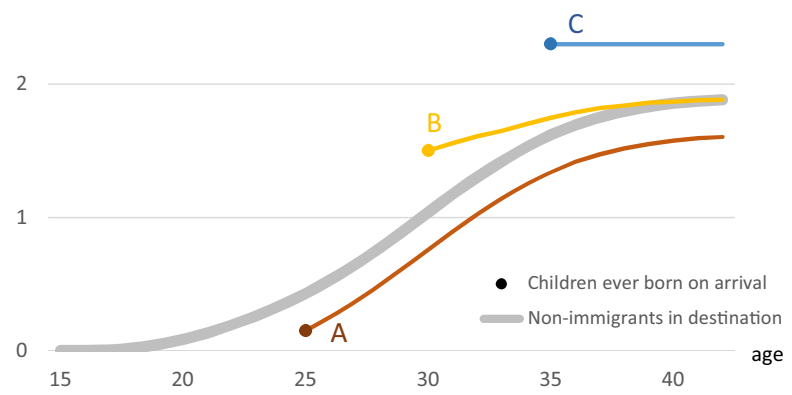

Fig. 1 A stylised presentation of fertility for natives and different immigrant groups 
births. Even with no more births after arrival, they will never be able to have the same completed fertility as non-immigrant women. For this reason, Fig. 1 helps to contextualise some of the limitations of the fertility measures that we have already discussed. Convergence between immigrants and natives in one measure may require divergence in another. For example, if immigrants have different cumulative fertility from the native average when they arrive, then convergence in completed fertility (the end points of the lines) will require divergence in fertility tempo (the slope of the lines), or vice versa. This also helps to highlight the difficulties of testing adaptation (which predicts fertility convergence) for immigrants who arrive as adults.

This visual framework can be expanded in several ways. For example, it is possible to compare different groups of immigrant women by birth cohort, country of birth, reason for migration etc, and to make comparisons with fertility patterns in origin countries. Moreover, fertility profiles can be used, as a first step at least, in studies that explore the hypotheses of immigrant fertility mentioned in the introduction. We return to these hypotheses in more detail in the discussion.

\section{Empirical Examples Using Register Data}

To show some examples of how this visual framework can be used, we apply it to Nordic register data. Most of our examples focus on Norway, where we use population register data which include complete cohorts of all immigrant women and all their live births in Norway. Immigrants are defined as people born abroad with foreign-born parents and grandparents and who have immigrated to Norway in order to stay for at least 6 months, with legal permission to stay. Immigration to Norway has been relatively high during the last decades, particularly after the 2004 EU enlargement, with many new immigrants from countries like Poland and Lithuania. For many years, Norway has had substantial immigration from Sweden and other European countries, and also from Non-Western countries such as Pakistan, the Philippines, Thailand, Somalia, Iraq, India and Russia.

Norwegian register data provide some information on previous births, including children born before immigration, which makes it possible to calculate parity. ${ }^{6}$ Since the Norwegian data on immigrants' characteristics are most comprehensive after 1990, and since we want to follow women longitudinally, we focus on women born 19751989. That includes almost 224,000 immigrant women. To compute their fertility profiles, we start by calculating their average number of births at arrival, by age of arrival, which is denoted by a dot in the figures that follow. For each subsequent year of age, we plot their cumulative fertility. The increase from year to year is thus the agespecific fertility rate for that arrival cohort at that age, and completed fertility is the average number of births at arrival plus the cumulative age-specific fertility rates from age at arrival onwards. This helps to explain how these fertility profiles show a combination of tempo and quantum.

\footnotetext{
$\overline{6}$ The information on children born before migration is based on data on children who have come to Norway and thus themselves in the population register, as well as some data on children born abroad who have not come to Norway. The latter is identified from information gathered when the mothers' give birth in Norway and are asked about the parity of the newborn. However, not all immigrant women give birth in Norway, and this may lead to some under-reporting of pre-migration births, particularly for women who arrive at higher ages, warranting some caution when interpreting the fertility profiles for the oldest women in our sample.
} 
Figure 2 displays cumulative fertility profiles for all immigrant women born 197589 , by age at arrival, and compared with the profile for non-immigrant women of the same birth cohorts (the thick grey line). ${ }^{7}$ The dots simultaneously mark the age of arrival and the average number of births at arrival. The figure describes several important aspects of immigrant fertility behaviour in Norway. First, immigrant women do not generally arrive as mothers of many children. On average, women arriving after age 23 (yellow dot) have had fewer births than Norwegian natives of the same age. Although fairly preliminary, this appears to provide some insights about the selectivity of immigrants with respect to their childbearing prior to arrival. As we show later in Fig. 5, even more insights about selection can be provided by comparing to immigrants' countries of origin.

Second, fertility profiles differ quite substantially between those who arrived before and after age 18 (dark green dot). For example, immigrant women who arrived as 15year-olds have an average fertility profile that does not increase substantially until their mid-20s, as compared with those who arrive at age 20. Those who came at this age have a steeper fertility profile at ages 20-25, implying a higher fertility tempo. They also end up with a higher completed fertility (quantum) than any of the other arrival cohorts. Age 25 is the most common arrival age in this sample, and is represented with a black line in the top panel of Fig. 2. For women who arrived after age 25, the slopes of most lines are similar to that of natives, which implies a similar fertility tempo. Since they arrive having had fewer births (on average) than their native peers, their completed fertility tends to be lower than that of natives.

With these examples, we can see how the visualisation of cumulative fertility profiles can provide simultaneous insights about the quantum and tempo of immigrant fertility. This may be particularly useful when studying hypotheses that make predictions about birth timing and numbers of children born. For example, the disruption hypothesis is usually defined as predicting a tempo delay, followed by a tempo increase, leading to quantum recovery.

Figure 2a summarises the childbearing profiles of all immigrant women who arrived at age 15-35, and thus gives a comprehensive overview. However, the main features may be presented in a more parsimonious form, as in the lower panel. Here, we have also added a line for child migrants, i.e. women who arrived in Norway before age 15 (the dashed grey line). Their fertility profile is relatively similar to that of nonimmigrant natives, but their cumulative fertility is somewhat higher before age 30 and somewhat lower after that. This indicates that although child immigrants start their childbearing somewhat earlier than non-immigrants, they also finish earlier, and end up with a completed fertility which is slightly lower than natives'. In the Appendix, Fig. 6 provides an example of our visual approach that includes an even more nuanced analysis of child migrants (in Sweden). This example further demonstrates how the fertility profiles can be tailored to the requirements of specific studies, such as investigations of the fertility adaptation of child migrants by age at arrival.

In Fig. 2, we pooled all birth cohorts from 1975 to 1989. This may mask important variation by birth cohort. In Fig. 3, we divide the sample of immigrants into three birth cohort groups: 1975-1979, 1980-1984 and 1985-1989. As the figures show, the oldest cohort (born 1975-1979) start out with a somewhat higher pre-migration fertility (at

\footnotetext{
$\overline{{ }^{7} \text { Each line includes women from }}$ all these birth cohorts; they are only distinguished by age at arrival.
} 


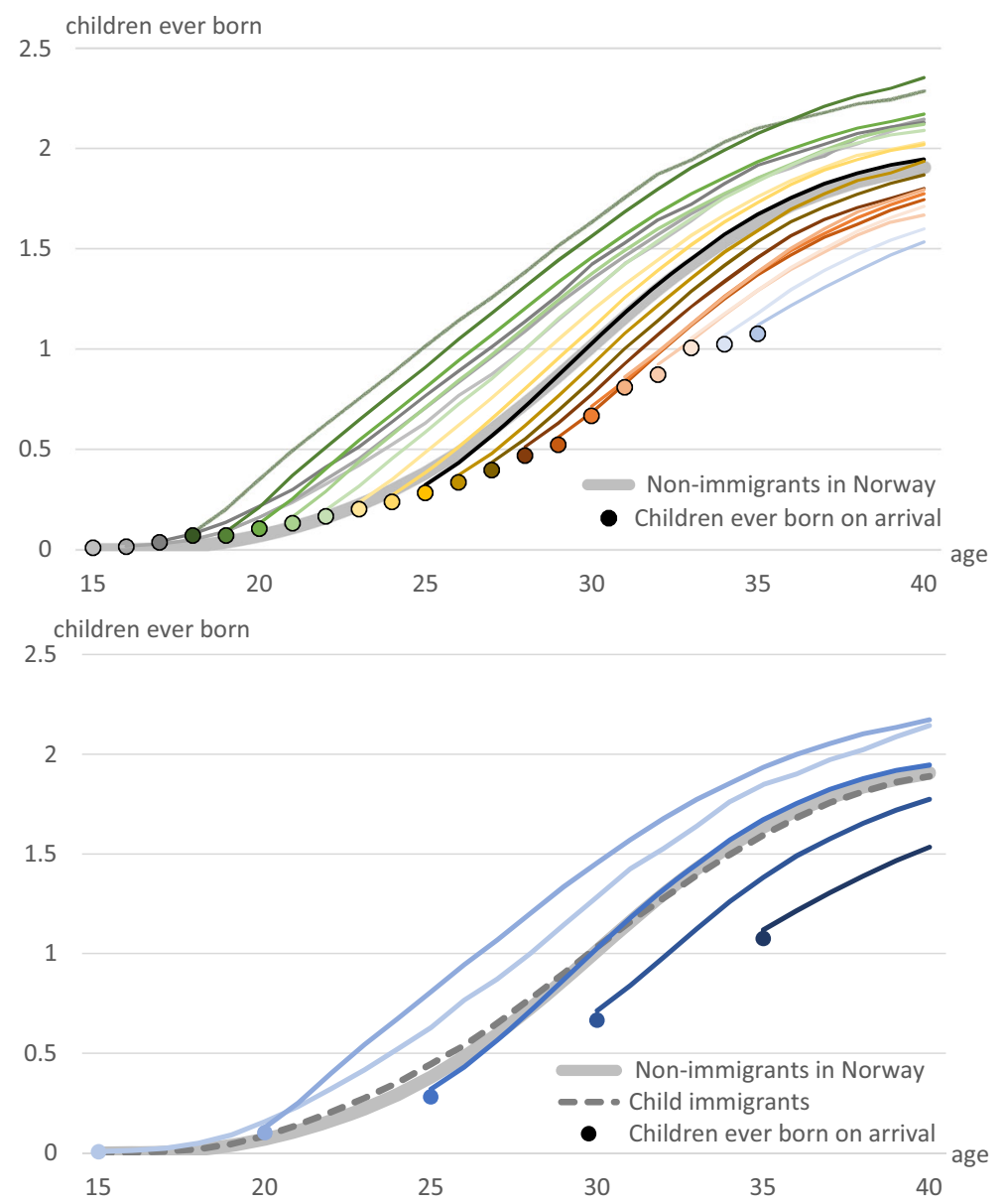

Fig. 2 Fertility profiles of natives and all immigrant women in Norway born 1975-1989, by age at arrival. Upper panel (a) shows all immigrant women, lower panel (b) shows selected arrival ages $(<15,15,20,25,30$ and 35 years)

least for those who arrived at age 25), and also display a higher birth intensity after arrival. For more recent birth cohorts, fertility is clearly lower, and they would need a high birth intensity in the years to come in order to reach the same completed fertility as their older predecessors. Figure 3 thus generates insights about the role of year of arrival (birth cohort + age at arrival) in determining immigrant fertility. As we have argued elsewhere, such evidence points towards the importance of explanations that relate to year of arrival (Tønnessen 2019), which include period fluctuations in migration policies, changes in origin-country fertility norms (and childhood socialisation), as well as changes in the selectivity and composition of immigration to Norway. Thus, the reduced steepness of the slopes for younger cohorts also conveys information about changing period fertility - and over the last decades, the period TFR for immigrants in Norway has declined (Tønnessen 2019). 


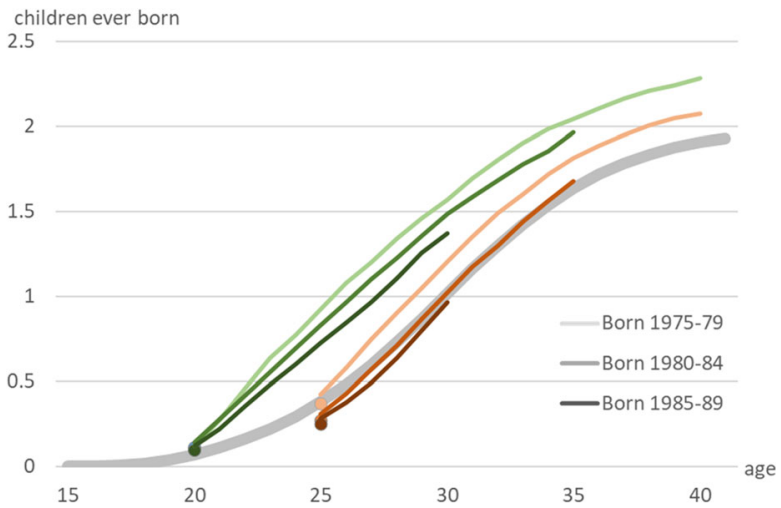

Fig. 3 Fertility profiles of natives and immigrant women in Norway by birth cohort and age at arrival (darker lines show younger birth cohorts). To improve readability, this figure displays only one line for natives born 1975-1989; however, also among native Norwegians, younger cohorts of women are giving birth at slightly later ages. This is shown in Fig. 7 in the Appendix

Figure 3 also shows how fertility profiles can be used to investigate different aspects of immigrant fertility, while controlling for (i.e. holding constant) age at arrival. In this case, our example compares the fertility profiles of women who all arrived at the same age (20 or 25), but in different years (i.e. different birth cohorts). However, similar plots can be generated for any other relevant characteristic, for example reasons for migration (see Fig. 4) or country of birth (see Fig. 5). Some of the variation by birth cohort that we see for immigrant women in Fig. 3 may relate to changes in the composition of migration to Norway, in particular after 2004 when many countries in Eastern Europe became members of the EU and labour migration to Norway increased substantially from countries such as Poland and Lithuania. Women with different reasons for migration (e.g. based on visa categories) may have very different fertility profiles. We can explore this by generating a plot like Fig. 4, which shows the three most common reasons for these cohorts: family migrants, refugees and labour migrants.

Not surprisingly, labour migrants have lower fertility profiles than the two other immigrant groups. Indeed, labour migrants have a similar fertility profile to that of natives, particularly those arriving at age 20 . Those arriving at age 25 have lower levels of completed fertility than the natives, and we can see that this is partly a result of their

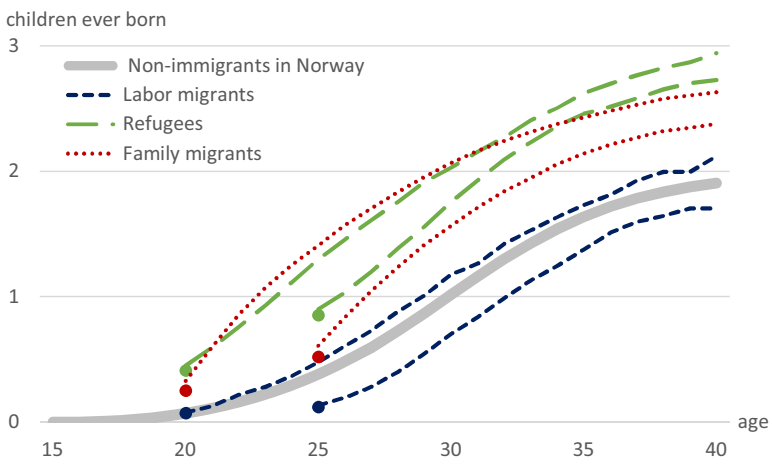

Fig. 4 Fertility profiles of natives and immigrant women in Norway born 1975-1989 by reason for arrival and age at arrival 
low fertility quantum at arrival. For family migrants, their tempo of fertility is very high — relative to the other groups - immediately after arrival. This can be assessed by looking at the gradient of the lines, showing that fertility tempo is elevated after arrival, which is a prediction that is often discussed in the literature on theories of immigrant fertility. Studies that focus on birth tempo can certainly be used to test whether this pattern of elevation exists, but the advantage of this visual approach is that we can also see how elevation is linked with cumulative (completed) fertility. Refugees do not display a similarly high tempo of fertility immediately after arrival, but on average they still end their childbearing with a higher completed fertility than family migrants (who arrive at the same age), for two reasons: (1) they arrive with a higher average number of children ever born, and (2) their fertility tempo is higher after age 30.

There may be important fertility differences also between women with the same reason for migration who arrived at the same age. For instance, among family migrants, women who already have some children before arrival may have a different birth behaviour after arrival compared with those who arrive childless. To explore this, we divided the family migrants into two groups by whether they had pre-migration children or not, and the results are shown in Appendix Fig. 8. The most striking feature of these fertility profiles is how similar the slopes after immigration are; they start out steep with high birth intensities, and then level somewhat off, no matter if the women arrive with or without children, or at age 20 or 25 . This indicates that being a family migrant is firmly linked to having a relatively high post-arrival fertility - which may not be very surprising as these women (usually) come to start or reunite a family.

As a final example, Fig. 5 shows how fertility profiles can be used to examine childbearing by country of birth, while also making comparisons with origin fertility profiles (i.e. profiles for the population who are resident in an immigrant's country of birth). In Fig. 5, this is done for two of the largest groups of immigrant women in Norway, those from Sweden and those from Pakistan. Data on age-specific fertility rates for these countries are provided by Eurostat for Sweden (Eurostat 2019b) and the

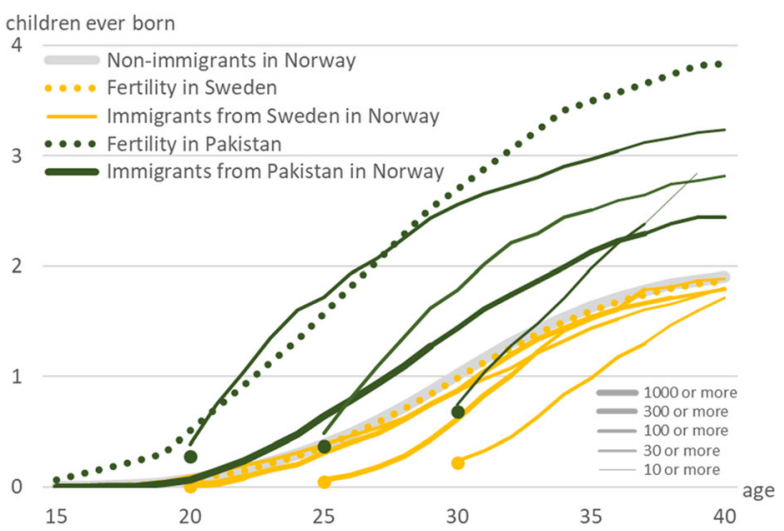

Fig. 5 Fertility profiles of immigrant women from Pakistan and Norway by age at arrival (up until 15, 20, 25 and 30 years), and of native women in Norway, Pakistan and Sweden, all born 1975-1989. This figure varies the widths of the lines for immigrants according to the population size of each group, by age. It also adds lines for the average fertility profiles in countries of origin. For Sweden, we use averages of the annual ASFR for 1990-2017 based on Eurostat data, whereas for Pakistan we use averages of the ASFR in 5-year age bands based on UN data for 1990-1995 to 2015-2020 
UN for Pakistan (United Nations 2019, by 5-year age groups). These origin fertility profiles are displayed with dotted lines (green for Pakistan and yellow for Sweden).

Fertility rates in Sweden are quite similar to those of Norwegians. However, Fig. 5 shows that Swedish women who move to Norway tend to have had fewer children at arrival than both native Norwegians, and women who remain in Sweden, at the same age. The fertility tempo of Swedish immigrants in Norway tends to be low immediately after migration, after which it increases, such that they have almost the same cumulative number of births as other women in Norway and Sweden by age 40, regardless of age at migration. These patterns are insightful because they demonstrate tempo and quantum variation for immigrants who are from a very similar origin (Sweden) to the destination (Norway) in terms of culture, family policies, and childbearing norms. The observed low levels of fertility prior to arrival, followed by recuperation to the same level of completed fertility as non-immigrants (in origin and destination) is therefore more likely attributable to explanations from the literature such as selection, anticipation and disruption.

For Pakistani immigrants, fertility tempo is particularly high immediately after migration (green solid lines in Fig. 5). For those arriving aged 20 or more, the initial slope is even steeper than for non-migrant women who are resident in Pakistan (dotted green line); however, after age 30, the fertility tempo for most of these Pakistani immigrants reduces and is similar to that of Norwegians. Also noteworthy are the considerable differences between Pakistani immigrant women in Norway in their numbers of children ever born at arrival - and women in Pakistan at the same age. These differences become larger with arrival age, increasing from a one-child difference for women arriving at age 25 to an almost two-child difference for those arriving at age 30. Although it may be possible to make inferences about selection by comparing immigrants with their destination, a more appropriate comparison for evaluating selection is immigrants versus their origin. In this case, we can see a clear variation in selection, which appears to play an important role in explaining the completed fertility of Pakistani immigrants.

One final innovation that we demonstrate in Fig. 5 is the ability of visual fertility profiles to account for variations in the sizes of immigrant populations. Some of the lines in the chart represent larger groups than others. In addition, the number of women in each group may decline over age due to emigration, death and (in the case of multiple birth cohorts that are grouped together) the fact that some women have not yet reached the relevant age. In Fig. 5, this is illustrated by the width of the lines. Different widths of line convey information which may be useful when assessing the importance, and in some cases the reliability, of different fertility profiles.

\section{Discussion}

In this paper, we have introduced a novel visual method for investigating the fertility of immigrants. We have described how it relates to alternative measures of immigrant fertility behaviour, and we have provided a number of examples to demonstrate the insights that this visual approach can produce. Here, we review some of the main advantages of the approach, as well as some of its main limitations, while also making recommendations for future research. 
One of the main advantages of the visual approach that we have demonstrated is its ability to both provide an overview - in summary - and show the complexity of migrant fertility in detail. Indeed, the amount of detail can be chosen by researchers, and the approach is flexible enough to study many subgroups and many characteristics. Compared with measures that summarise fertility using single numbers, visual plots of fertility profiles combine an ability to show the entire childbearing careers of immigrants with an ability to convey detailed information about (1) average number of children born before arrival, (2) variations in children ever born by age, (3) birth tempo after arrival and (4) completed fertility. By integrating longitudinal information on fertility by age, age at arrival and duration of residence, this visual approach also enables these factors to be investigated alongside studies of other characteristics such as birth cohort, country of birth and reasons for migration. The approach is flexible enough to study a variety of other factors, such as education, health or residential context, if data permit. It is even possible to extend this approach to study parity, for example, by including additional visual information that shows the share of the group who have had one birth, two births etc. Another visual approach is to plot these shares on the vertical axis, instead of children ever born. In this case, dots could be used to show the share who have had their first birth (or had reached other parities) before arrival, and profiles could show how this share increases after arrival. We also note that visual fertility profiles could use many different definitions of 'immigrant', including those based on residency or citizenship. As noted earlier, it is also possible to choose (and plot) different comparison groups. For example, instead of comparing immigrant women with (all) non-immigrant women, it is also possible to compare subgroups (e.g. by education).

This framework may also be used to help determine the type of data that need to be collected in order to provide a complete picture of migrant's fertility. In many countries and contexts, data on immigrant fertility are inadequate. Even the register data used in this paper are probably unlikely to include all pre-migration births (see footnote 6), which may partly explain why the dots showing pre-migration births for those arriving after mid-30s are generally low.

It is beyond the scope of this paper to discuss all of the hypotheses that have been proposed in order to predict immigrant fertility behaviour. These are presented and discussed in detail elsewhere (Kulu and González-Ferrer 2014; Milewski 2010a). Nevertheless, the visual framework presented in this paper allows us to shed light on many of the most commonly studied hypotheses concerning immigrant fertility. For example, the hypothesis of interrelation of events posits that for many women, migration is inextricably linked to family formation. For this reason, and perhaps other reasons such as anticipation, immigrant women are often predicted to have an elevated (i.e. higher) fertility tempo immediately after migration. We see some evidence in support of this hypothesis for Norway, where fertility profiles are particularly steep immediately after migration for young family migrants (Fig. 4).

The hypothesis of childhood socialisation points towards the role of countries of origin in shaping women's fertility behaviour. In Fig. 5, childhood socialisation may be one reason why fertility levels differ between immigrants from Pakistan and Sweden. However, the fertility profile of immigrants, including the dot showing number of 
children born at arrival, is not fully congruent with origin fertility profiles, neither for Pakistani nor Swedish immigrants, indicating that other factors also play a role. One of them may be selection, which suggests that immigrants are different from non-migrants who reside in their country of birth. Figure 5 provides some evidence of selection, particularly for Pakistani women arriving at ages 25 and 30. Of course, this selection may be related to various factors, including other hypotheses such as disruption, which predicts the postponement of births until after migration, a pattern that may be evident for Swedish immigrants to Norway (in Fig. 5).

We also argue that cumulative fertility profiles can help researchers to understand the complexities of the adaptation hypothesis, which predicts that the longer an immigrant stays in a new country, the more their fertility will resemble 'typical' fertility in this destination. As shown in our stylised example, adaptation may be interpreted and measured in different ways, some of which may be contradictory. For instance, as shown in Fig. 5, Swedish immigrant women who arrive at age 25 have a similar fertility tempo as non-immigrant Norwegians immediately after arrival, but after some years their profiles become steeper than those for the natives, indicating no adaptation in fertility tempo. At the same time, this change in tempo helps to produce a completed fertility that is almost identical to the Norwegian level, indicating adaptation, but only as measured by completed fertility. These nuances of adaptation are made explicit by our approach.

Turning to the limitations of our approach, one of its main drawbacks is the requirements that it places on data. Basically, the fertility profiles only require data on the average number of pre-migration births and age-specific fertility rates for groups of immigrant women by arrival age. However, these data are unfortunately not available in all contexts, and in particular data on pre-migration births may be scarce. In countries with good population data, it can be relatively straightforward to identify children born abroad to immigrant women if these children have immigrated with their mother. Identifying children left behind is usually more challenging. One can assume that most mothers with young children will migrate with these children; however, women who arrive at older ages may have some (older) children who remain in their origin country. This warrants caution when using our approach to study the fertility of immigrant women who arrive towards the end of their childbearing period since their cumulative fertility at arrival may be underreported. If reliable data on pre-migration births are lacking, alternative data may be available for similar groups in other countries, or in some cases it may be possible to make use of data from origin countries (acknowledging that emigrants are likely to be a select group), or to assume that immigrants' pre-migration fertility is similar to a particular population in the destination (depending on the scope of the research). In contexts that do not have general fertility data of similar quality to register data, other sources such as surveys may provide information on both pre-migration births, arrival age and fertility by age, but then sample size may limit the possibility for investigating subgroups. 
Another drawback, which this approach shares with several other fertility measures, is that it cannot compete with period measures such as the TFR when it comes to giving an instant (single) measure of contemporary fertility among immigrants. In particular, we have to wait until women are at the end of their childbearing before we can measure their completed fertility. That said, this visual approach can be used to plot the timeliest data, to place it into a more comprehensive context, and to assess whether younger cohorts of women seem to be following older women's fertility profiles.

Related to this, and as a further limitation, we note that this visual approach can also produce numerous highly complex plots. This complexity can become confusing, especially when trying to summarise specific aspects of immigrant fertility. As with any measure, there is a trade-off between summary and detail, which can be mitigated to some extent by showing several figures at different levels of detail, or by using 'small multiples' (i.e. many small plots in one panel, each with limited but harmonised detail) (Tufte 2001). We expect that researchers will also be guided by their interests and research questions, including as a way of deciding whether to provide an overview of all immigrants or to focus on specific groups.

\section{Recommendations for Future Research}

In this paper, we have introduced what we hope will be a useful addition to the methodological toolbox of migration scholars due to its flexibility and its ability to convey complex information. Although we have demonstrated many of the advantages of this visual approach, it is only through future research that its strengths and weaknesses can be truly uncovered. In particular, we recommend that researchers try to implement a similar approach in different contexts, and for studying different aspects of immigrant fertility, including to study subgroups, examine different characteristics, decompose differences, vary comparison groups and to incorporate the visualisation of parity. Furthermore, even in contexts where data limitations make it difficult to plot fertility profiles, we hope that the visualisations presented here can illuminate some of the challenges of measuring immigrant fertility, raise awareness of each measure's strengths and weaknesses, and guide researchers when choosing the most relevant approach for their study.

Acknowledgements Open Access funding provided by OsloMet - Oslo Metropolitan University. We thank the many colleagues who provided helpful comments in the development of this research.

Funding Information This work was supported by Statistics Norway and the Swedish Research Council for Health, Working life and Welfare (FORTE), grant numbers 2016-07105 and 2018-00310. It was also supported by the Swedish Research Council (Vetenskapsrådet) via grant number 2017-01021 and via the Swedish Initiative for Research on Microdata in the Social and Medical Sciences (SIMSAM), grant number 340-2013-5164. 


\section{Appendix}

Table 1 Examples of approaches for measuring immigrant fertility

\begin{tabular}{|c|c|c|}
\hline Method/measure & Data/source & Some examples that study immigrant fertility \\
\hline \multicolumn{3}{|l|}{ Total fertility rates } \\
\hline TFR/ASFR comparison ${ }^{\mathrm{a}}$ & Own-child method ${ }^{b}$ & $\begin{array}{l}\text { (Abbasi-Shavazi and McDonald 2000; Bélanger and } \\
\text { Gilbert 2006; Coleman and Dubuc 2010; Dubuc 2012; } \\
\text { Goldstein and Goldstein 1981; Ng and Nault 1997) }\end{array}$ \\
\hline TFR/ASFR comparison ${ }^{\mathrm{a}}$ & $\begin{array}{l}\text { Survey or } \\
\text { administrative } \\
\text { data on births by } \\
\text { age and period }\end{array}$ & $\begin{array}{l}\text { (Coleman 1994; Dormon 2014; Fokkema et al. 2008; } \\
\text { Héran and Pison 2007; Iliffe 1978; Robards et al. 2011; } \\
\text { Toulemon 2004; Tromans et al. 2007; Van Landschoot } \\
\text { et al. 2014; Zumpe et al. 2012) }\end{array}$ \\
\hline Adjusted TFR comparison ${ }^{\mathrm{a}}$ & $\begin{array}{l}\text { Survey or } \\
\text { administrative } \\
\text { data }\end{array}$ & $\begin{array}{l}\text { (Kulu et al. 2019; Persson and Hoem 2014; Toulemon } \\
\text { 2006) }\end{array}$ \\
\hline \multicolumn{3}{|c|}{ Measures based on event history approaches } \\
\hline $\begin{array}{l}\text { Event history: } \\
\text { first births only }\end{array}$ & $\begin{array}{l}\text { Survey or } \\
\text { administrative } \\
\text { data on birth } \\
\text { histories }\end{array}$ & $\begin{array}{l}\text { (Milewski 2007; Mussino et al. 2015; Mussino and van } \\
\text { Raalte 2013; Scott and Stanfors 2011) }\end{array}$ \\
\hline $\begin{array}{l}\text { Event history: } \\
\text { first births only }\end{array}$ & $\begin{array}{l}\text { Survey or } \\
\text { administrative } \\
\text { data on birth } \\
\text { histories }\end{array}$ & $\begin{array}{l}\text { (Malmberg and Andersson 2019; Mussino and Strozza } \\
\text { 2012) }\end{array}$ \\
\hline $\begin{array}{l}\text { Event history: } \\
\text { multiple parities }\end{array}$ & $\begin{array}{l}\text { Survey or } \\
\text { administrative } \\
\text { data on birth } \\
\text { histories }\end{array}$ & $\begin{array}{l}\text { (Andersson 2004; González-Ferrer et al. 2017; Jensen and } \\
\text { Ahlburg 2004; Kulu 2005; Lindstrom and Giorguli } \\
\text { Saucedo 2002, 2007; Milewski 2010b; Mussino et al. } \\
\text { 2010; Puur et al. 2017; White et al. 1995; Wolf 2016) }\end{array}$ \\
\hline \multicolumn{3}{|c|}{ Measures of number of children ever born } \\
\hline Linear regression & $\begin{array}{l}\text { Survey or census } \\
\text { data on children } \\
\text { ever born }\end{array}$ & $\begin{array}{l}\text { (Bach 1981; Blau 1991; Fernández and Fogli 2006, 2009; } \\
\text { Ford 1990; Goldstein and Goldstein 1983; Hwang and } \\
\text { Saenz 1997; Kahn 1988, 1994; Lopez and Sabagh } \\
\text { 1978; Ritchey 1975; Sly 1970) }\end{array}$ \\
\hline Linear regression & Own-child method ${ }^{b}$ & (Bean and Swicegood 1982; Ford 1990) \\
\hline Count models & $\begin{array}{l}\text { Survey or census } \\
\text { data on children } \\
\text { ever born }\end{array}$ & $\begin{array}{l}\text { (Adserà and Ferrer 2014; Chattopadhyay et al. 2006; Choi } \\
\text { 2014; Frank and Heuveline 2005; Lindstrom and } \\
\text { Giorguli Saucedo 2002; Mayer and Riphahn 2000; } \\
\text { Ortensi 2015) }\end{array}$ \\
\hline Completed fertility & $\begin{array}{l}\text { Survey or census } \\
\text { data on children } \\
\text { ever born }\end{array}$ & $\begin{array}{l}\text { (Friedlander and Goldscheider 1978; Mayer and Riphahn } \\
\text { 2000; Parrado and Morgan 2008; Rosenwaike 1973; } \\
\text { Young 1991) }\end{array}$ \\
\hline Cumulative cohort fertility & $\begin{array}{l}\text { Census or } \\
\text { administrative } \\
\text { data on birth } \\
\text { histories }\end{array}$ & $\begin{array}{l}\text { (Alders 2000; Bagavos et al. 2007; Fokkema et al. 2008; } \\
\text { Friedlander and Goldscheider 1978; Garssen and } \\
\text { Nicolaas 2008) }\end{array}$ \\
\hline
\end{tabular}

Some of these examples use multiple measures, including those from different categories

a TFR (total fertility rate), ASFR (age-specific fertility rate) — see text for definitions

b The own-child method uses data on the number of children resident in a mother's household in order to estimate the mother's childbearing

c Parity refers to whether a child is the first-born, second-born etc 
children ever born

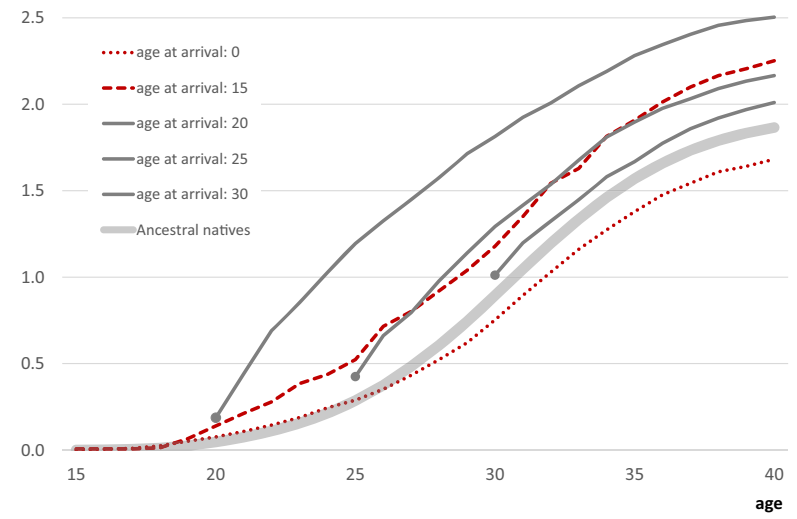

Fig. 6 Fertility profiles of immigrants who arrived in Sweden as young adults as compared with those arriving as infants (for those born in 1976). Estimates are produced using register data for the entire population who were born in 1976 and who did not die or emigrate before age 40. It plots the profiles for (1) ancestral natives (Swedish-born children of Swedish-born parents) and (2) immigrants who arrived in Sweden at ages 0, 15, 20, 25 and 30. Each line plots the average cumulate number of children ever born for each arrival cohort. As well as providing another example of how longitudinal fertility profiles can illustrate differences in tempo and quantum over the entire reproductive life course, this example shows how the comparison group can be varied depending on the research question. As well as comparing with natives, this figure shows that the comparison group could be immigrants who arrive as infants (when age 0 ). In this case, the figure shows that arriving in young adulthood (at age 15, and even more so at age 20) is associated with a much higher tempo of fertility, especially from ages 20-30, and a higher level of completed fertility, as compared with arriving as an infant. There is an average difference of more than 0.5 children in completed fertility comparing immigrants arriving aged 15 with those arriving in the first year of their life. Given that these two groups arrive before commencing childbearing, some might interpret this as evidence of adaptation

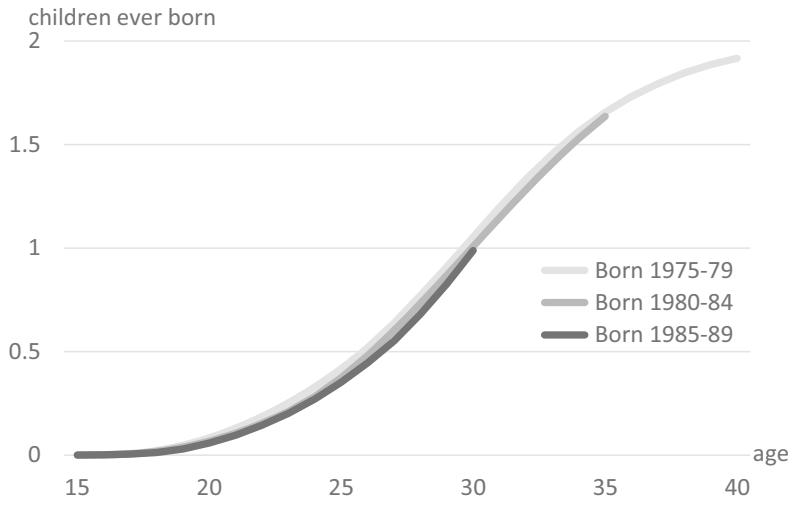

Fig. 7 Fertility profiles of non-immigrant Norwegians, by birth cohorts 


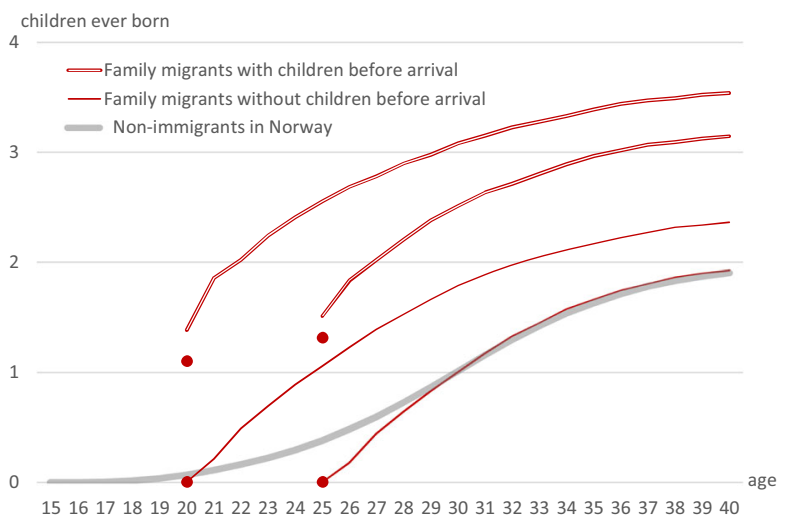

Fig. 8 Fertility profiles of family migrants (born 1975-1989) with and without children before arrival. The vertical distances between the dots and the start of the lines can be explained by births given during the year of arrival

Open Access This article is licensed under a Creative Commons Attribution 4.0 International License, which permits use, sharing, adaptation, distribution and reproduction in any medium or format, as long as you give appropriate credit to the original author(s) and the source, provide a link to the Creative Commons licence, and indicate if changes were made. The images or other third party material in this article are included in the article's Creative Commons licence, unless indicated otherwise in a credit line to the material. If material is not included in the article's Creative Commons licence and your intended use is not permitted by statutory regulation or exceeds the permitted use, you will need to obtain permission directly from the copyright holder. To view a copy of this licence, visit http://creativecommons.org/licenses/by/4.0/.

\section{References}

Abbasi-Shavazi, M. J., \& McDonald, P. (2000). Fertility and multiculturalism: immigrant fertility in Australia, 1977-1991. International Migration Review, 34(1), 215-242.

Adserà, A., \& Ferrer, A. (2016). The fertility of married immigrant women to Canada. International Migration Review, 50(2), 475-505. https://doi.org/10.1111/imre.12114.

Adsera, A., \& Ferrer, A. (2014). Factors influencing the fertility choices of child immigrants in Canada. Population Studies, 68(1), 65-79.

Alders, M. (2000). Cohort fertility of migrant women in the Netherlands: developments in fertility of women born in Turkey, Morocco, Suriname, and the Netherlands Antilles and Aruba. Department of Population Division, statistics Netherlands, paper for the BSPS-NVD-URU conference, Utrecht, 31 August-1 September, 2000.

Andersson, G. (2004). Childbearing after migration: fertility patterns of foreign-born women in Sweden. International Migration Review, 38(2), 747-774. https://doi.org/10.1111/j.1747-7379.2004.tb00216.x.

Bach, R. L. (1981). Migration and fertility in Malaysia: a tale of two hypotheses. International Migration Review, 15(3), 502-521. https://doi.org/10.2307/2545493.

Bagavos, C., Tsimbos, C., \& Verropoulou, G. (2007). Native and migrant fertility patterns in Greece: a cohort approach. European Journal of Population / Revue européenne de Démographie, 24, 245-263. https://doi.org/10.1007/s10680-007-9142-6.

Bean, F. D., \& Swicegood, G. (1982). Generation, female education and Mexican American fertility. Social Science Quarterly (University of Texas Press), 63(1), 131-144.

Bélanger, A., \& Gilbert, S. (2006). The fertility of immigrant women and their Canadian-born daughters. In Report on the Demographic Situation in Canada, 2002 (pp. 127-151). Statistics Canada. 
Blau, F. D. (1991). The fertility of immigrant women: evidence from high fertility source countries. National Bureau of Economic Research Working Paper Series, No. 3608. http:/www.nber.org/papers/w3608. Accessed 18 September 2011.

Chattopadhyay, A., White, M. J., \& Debpuur, C. (2006). Migrant fertility in Ghana: selection versus adaptation and disruption as causal mechanisms. Population Studies, 60(2), 189-203.

Choi, K. (2014). Fertility in the context of Mexican migration to the United States: a case for incorporating the pre-migration fertility of immigrants. Demographic Research, 30, 703-738. https://doi.org/10.4054 /DemRes.2014.30.24.

Coleman, D. A. (1994). Trends in fertility and intermarriage among immigrant populations in Western Europe as measures of integration. Journal of Biosocial Science, 26(1), 107-136. https://doi.org/10.1017 /S0021932000021106.

Coleman, D. A., \& Dubuc, S. (2010). The fertility of ethnic minorities in the UK, 1960s-2006. Population Studies, 64(1), 19-41. https://doi.org/10.1080/00324720903391201.

Courgeau, D., \& Lelievre, E. (1991). The event history approach in demography. Population: An English Selection, 3, 63-79.

Dormon, O. (2014). Childbearing of UK and non-UK born women living in the UK-2011 census data. Office for National Statistics. http://www.ons.gov.uk/ons/dep171766_350433.pdf. Accessed 5 February 2014.

Dubuc, S. (2012). Immigration to the UK from high-fertility countries: intergenerational adaptation and fertility convergence. Population and Development Review, 38(2), 353-368. https://doi.org/10.1111 j.1728-4457.2012.00496.x.

Eurostat. (2019a). Migration and migrant population statistics - Statistics Explained. https://ec.europa. eu/eurostat/statistics-explained/index.php/Migration_and_migrant_population_statistics. Accessed 4 July 2019.

Eurostat. (2019b). Fertility rates by age (demo_frate). Downloaded 2 July 2019 from http://appsso.eurostat.ec. europa.eu/nui/show.do?dataset=demo_frate\&lang=en.

Fernández, R., \& Fogli, A. (2006). Fertility: the role of culture and family experience. Journal of the European Economic Association, 4(2-3), 552-561.

Fernández, R., \& Fogli, A. (2009). Culture: an empirical investigation of beliefs, work, and fertility. American Economic Journal: Macroeconomics, 1(1), 146-177. https://doi.org/10.1257/mac.1.1.146.

Fokkema, T., de Valk, H., de Beer, J., \& Van Duin, C. (2008). The Netherlands: childbearing within the context of a "Poldermodel" society. Demographic Research, 19, 743-794. https://doi.org/10.4054 /DemRes.2008.19.21.

Ford, K. (1990). Duration of residence in the United States and the fertility of US immigrants. International Migration Review, 24(1), 34-68. https://doi.org/10.2307/2546671.

Frank, R., \& Heuveline, P. (2005). A cross-over in Mexican and Mexican-American fertility rates. Demographic Research, 12, 77-104. https://doi.org/10.4054/DemRes.2005.12.4.

Frejka, T., \& Calot, G. (2001a). Cohort reproductive patterns in low-fertility countries. Population and Development Review, 27(1), 103-132. https://doi.org/10.1111/j.1728-4457.2001.00103.x.

Frejka, T., \& Calot, G. (2001b). Cohort reproductive patterns in the Nordic countries. Demographic Research, 5, 125-186. https://doi.org/10.4054/DemRes.2001.5.5.

Friedlander, D., \& Goldscheider, C. (1978). Immigration, social change and cohort fertility in Israel. Population Studies, 32(2), 299-317. https://doi.org/10.2307/2173563.

Garssen, J., \& Nicolaas, H. (2008). Fertility of Turkish and Moroccan women in the Netherlands: adjustment to native level within one generation. Demographic Research, 19, 1249-1280. https://doi.org/10.4054 /DemRes.2008.19.33.

Goldstein, S., \& Goldstein, A. (1981). The impact of migration on fertility: an 'own children' analysis for Thailand. Population Studies, 35(2), 265-284. https://doi.org/10.2307/2174939.

Goldstein, S., \& Goldstein, A. (1983). Migration and fertility in peninsular Malaysia. A Rand Note, Prepared for The Agency for International Development, [N-1860-AID]. http://www.rand.org/pubs/notes/N1860. html. Accessed 30 October 2011.

González-Ferrer, A., Castro Martín, T., Kraus, E., \& Eremenko, T. (2017). Childbearing patterns among immigrant women and their daughters in Spain: over-adaptation or structural constraints. Demographic Research, 37(19), 599-634. https://doi.org/10.4054/DemRes.2017.37.19.

Hajnal, J. (1947). The analysis of birth statistics in the light of the recent international recovery of the birthrate. Population Studies, 1(2), 137-164. https://doi.org/10.2307/2172285.

Haug, W., Compton, P., \& Courbage, Y. (2002). The demographic characteristics of immigrant populations. Strasbourg: Council of Europe. 
Héran, F., \& Pison, G. (2007). Two children per woman in France in 2006: are immigrants to blame? Population and Societies, 432(March 2007) https://www.ined.fr/fichier/s_rubrique/19100/pesa432bis.en. pdf.

Hill, J. A. (1913). Comparative fecundity of women of native and foreign parentage in the United States. Publications of the American Statistical Association, 13(104), 583-604. https://doi.org/10.2307/2965013.

Hinde, A. (1998). Demographic methods. London: Routledge.

Hobcraft, J., \& Murphy, M. (1986). Demographic event history analysis: a selective review. Population Index, 52(1), 3-27. https://doi.org/10.2307/3644790.

Hoem, J. M., \& Mureșan, C. (2011). An extension of the conventional TFR. European Journal of Population / Revue européenne de Démographie, 27(4), 389-402. https://doi.org/10.1007/s10680-011-9247-9.

Hoem, J. M., \& Nedoluzhko, L. (2014). Pre- and post-migration fertility (Stockholm research reports in demography). Stockholm University http:/www.suda.su.se/SRRD/SRRD_2014_18.pdf. Accessed 10 November 2014.

Hoem, J. M., \& Nedoluzhko, L. (2016). The dangers of using 'negative durations' to estimate pre- and postmigration fertility. Population Studies, 70(3), 359-363. https://doi.org/10.1080/00324728.2016.1221442.

Hwang, S.-S., \& Saenz, R. (1997). Fertility of Chinese immigrants in the U.S.: testing a fertility emancipation hypothesis. Journal of Marriage and the Family, 59(1), 50. https://doi.org/10.2307/353661.

Iliffe, L. (1978). Estimated fertility rates of Asian and West Indian immigrant women in Britain, 1969-74. Journal of Biosocial Science, 10(2), 189-197.

Jensen, E., \& Ahlburg, D. (2004). Why does migration decrease fertility? Evidence from the Philippines. Population Studies, 58(2), 219-231. https://doi.org/10.1080/0032472042000213686.

Jonsson, S. H., \& Rendall, M. S. (2004). The fertility contribution of Mexican immigration to the United States. Demography, 41(1), 129-150.

Kahn, J. R. (1988). Immigrant selectivity and fertility adaptation in the United States. Social Forces, 67(1), $108-128$.

Kahn, J. R. (1994). Immigrant and native fertility during the 1980s: adaptation and expectations for the future. International Migration Review, 28(3), 501-519. https://doi.org/10.2307/2546818.

Kraus, E. K. (2019). Family formation trajectories across borders: a sequence analysis approach to Senegalese migrants in Europe. Advances in Life Course Research, 100290, 100290. https://doi.org/10.1016/j. alcr.2019.100290.

Kuczynski, R. R. (1932). Fertility and reproduction. Falcon Press.

Kulu, H. (2005). Migration and fertility: competing hypotheses re-examined. European Journal of Population / Revue européenne de Démographie, 21(1), 51-87. https://doi.org/10.1007/s10680-005-3581-8.

Kulu, H., \& González-Ferrer, A. (2014). Family dynamics among immigrants and their descendants in Europe: current research and opportunities. European Journal of Population, 30(4), 411-435. https://doi.org/10.1007/s10680-014-9322-0.

Kulu, H., \& Milewski, N. (2007). Family change and migration in the life course: An introduction. Demographic Research, 17, 567-590. https://doi.org/10.4054/DemRes.2007.17.19.

Kulu, H., Milewski, N., Hannemann, T., \& Mikolai, J. (2019). A decade of life-course research on fertility of immigrants and their descendants in Europe. Demographic Research, 40, 1345-1374. https://doi. org/10.4054/DemRes.2019.40.46.

Lindstrom, D. P., \& Giorguli Saucedo, S. (2002). The short- and long-term effects of U.S. migration experience on Mexican women's fertility. Social Forces, 80(4), 1341-1368. https://doi.org/10.1353 /sof.2002.0030.

Lindstrom, D. P., \& Giorguli Saucedo, S. (2007). The interrelationship of fertility, family maintenance and Mexico-U.S. migration. Demographic Research, 17, 821-858. https://doi.org/10.4054 /DemRes.2007.17.28.

Lopez, D. E., \& Sabagh, G. (1978). Untangling structural and normative aspects of the minority status-fertility hypothesis. American Journal of Sociology, 83(6), 1491-1497. https://doi.org/10.1086/226710.

Malmberg, B., \& Andersson, E. K. (2019). Adolescent neighbourhood context and transition to parenthood: a longitudinal study. Population, Space and Place, e2228. https://doi.org/10.1002/psp.2228.

Mayer, J., \& Riphahn, R. T. (2000). Fertility assimilation of immigrants: evidence from count data models. Journal of Population Economics, 13(2), 241-261.

Milewski, N. (2007). First child of immigrant workers and their descendants in West Germany: interrelation of events, disruption, or adaptation? Demographic Research, 17, 859-896. https://doi.org/10.4054 /DemRes.2007.17.29.

Milewski, N. (2010a). Introduction. InFertility of immigrants: a two-generational approach in Germany. Berlin Heidelberg: Springer. http://link.springer.com.gate2.library.lse.ac.uk/chapter/10.1007/978-3-64203705-4_1. Accessed 9 March 2015. 
Milewski, N. (2010b). Immigrant fertility in West Germany: is there a socialization effect in transitions to second and third births? European Journal of Population / Revue européenne de Démographie, 26(3), 297-323. https://doi.org/10.1007/s10680-010-9211-0.

Milewski, N., \& Mussino, E. (2019). Editorial on the special issue 'New aspects on migrant populations in Europe: norms, attitudes and intentions in fertility and family planning,'. Comparative Population Studies, 43, 371-398.

Mills, M. (2011). Introducing survival and event history analysis. Sage Publications Ltd..

Murphy, M. (1995). The impact of migration on population composition: the British case. In S. Voets, J. J. Schoorl, \& B. de Bruijn (Eds.), The demographic consequences of international migration (pp. 207-224). The Hague: Netherlands Interdisciplinary Demographic Institute.

Mussino, E., Gabrielli, G., Paterno, A., Strozza, S., \& Terzera, L. (2015). Motherhood of foreign women in Lombardy: testing the effects of migration by citizenship. Demographic Research, 33, 653-664. https://doi.org/10.4054/DemRes.2015.33.23.

Mussino, E., Iaccarino, C., Prati, S., \& Strozza, S. (2010). Short term reproductive behaviour of foreign women who became mothers between 2002-2006 in Italy. Vienna Yearbook of Population Research, 2009, 63-82. https://doi.org/10.1553/populationyearbook2009s63.

Mussino, E., \& Strozza, S. (2012). The fertility of immigrants after arrival: the Italian case. Demographic Research, 26, 99-130. https://doi.org/10.4054/DemRes.2012.26.4.

Mussino, E., \& van Raalte, A. A. (2013). Immigrant fertility: a comparative study between Italy and Russia. International Migration, 51(2), 148-164. https://doi.org/10.1111/j.1468-2435.2012.00760.x.

$\mathrm{Ng}$, E., \& Nault, F. (1997). Fertility among recent immigrant women to Canada, 1991: an examination of the disruption hypothesis. International Migration, 35(4), 559-580. https://doi.org/10.1111/14682435.00027.

Ní Bhrolcháin, M. (1992). Period paramount? A critique of the cohort approach to fertility. The Population and Development Review, 18(4), 599-629.

Ní Bhrolcháin, M. (2011). Tempo and the TFR. Demography, 48(3), 841-861. https://doi.org/10.1007 /s13524-011-0033-4.

Ortensi, L. E. (2015). Engendering the fertility-migration nexus: the role of women's migratory patterns in the analysis of fertility after migration. Demographic Research, 32, 1435-1468. https://doi.org/10.4054 /DemRes.2015.32.53.

Østby, L. (2002). The demographic characteristics of immigrant population in Norway. Oslo: Statistics Norway.

Parrado, E. A. (2011). How high is Hispanic/Mexican fertility in the United States? Immigration and tempo considerations. Demography, 48(3), 1059-1080. https://doi.org/10.1007/s13524-011-0045-0.

Parrado, E. A., \& Flippen, C. A. (2012). Hispanic fertility, immigration, and race in the twenty-first century. Race and Social Problems, 4(1), 18-30. https://doi.org/10.1007/s12552-012-9063-9.

Parrado, E. A., \& Morgan, S. P. (2008). Intergenerational fertility among Hispanic women: new evidence of immigrant assimilation. Demography, 45(3), 651-671. https://doi.org/10.1353/dem.0.0023.

Persson, L., \& Hoem, J. M. (2014). Immigrant fertility in Sweden, 2000-2011: a descriptive note. Demographic Research, 30, 887-898. https://doi.org/10.4054/DemRes.2014.30.30.

Preston, S., Heuveline, P., \& Guillot, M. (2000). Demography: measuring and modeling population processes. Wiley-Blackwell.

Puur, A., Rahnu, L., Abuladze, L., Sakkeus, L., \& Zakharov, S. (2017). Childbearing among first- and secondgeneration Russians in Estonia against the background of the sending and host countries. Demographic Research, 36, 1209-1254. https://doi.org/10.4054/DemRes.2017.36.41.

Ritchey, P. N. (1975). The effect of minority group status on fertility: a re-examination of concepts. Population Studies, 29(2), 249-257. https://doi.org/10.2307/2173510.

Robards, J., Berrington, A., \& Hinde, A. (2011). Estimating fertility rates using the ONS longitudinal studywhat difference does the inclusion of non-continually resident members make? Population Trends, 144(1), 33-47. https://doi.org/10.1057/pt.2011.10.

Rosenwaike, I. (1973). Two generations of Italians in America: their fertility experience. International Migration Review, 7(3), 271-280.

Scott, K., \& Stanfors, M. (2011). Can immigrant fertility rejuvenate the European population? Evidence from Sweden. Sweden: Center for Economic Demography and Department of Economic History, Lund University.

Singley, S. G., \& Landale, N. S. (1998). Incorporating origin and process in migration-fertility frameworks: the case of Puerto Rican women. Social Forces, 76(4), 1437-1464. https://doi.org/10.2307/3005841.

Sly, D. F. (1970). Minority-group status and fertility: an extension of Goldscheider and Uhlenberg. American Journal of Sociology, 76(3), 443-459. 
Sobotka, T. (2008). Overview chapter 7: the rising importance of migrants for childbearing in Europe. Demographic Research, 19, 225-248. https://doi.org/10.4054/DemRes.2008.19.9.

Sobotka, T., \& Lutz, W. (2011). Misleading policy messages derived from the period TFR: should we stop using it? Comparative Population Studies, 35(3) http://www.comparativepopulationstudies.de/index. $\mathrm{php} / \mathrm{CPoS} /$ article/view/54. Accessed 27 December 2013.

Steele, F. (2005). Event history analysis (ESRC) (no. NCRM/004). ESRC National Centre for Research Methods. http://eprints.ncrm.ac.uk/88/1/MethodsReviewPaperNCRM-004.pdf. Accessed 21 September 2011.

Steele, F., Joshi, H., Kallis, C., \& Goldstein, H. (2007). Changes in the relationship between the outcomes of cohabiting partnerships and fertility among young British women: evidence from the 1958 and 1970 Birth Cohort Studies. http://eprints.ioe.ac.uk/5936/. Accessed 1 June 2016.

Toulemon, L. (2004). Fertility among immigrant women: new data, a new approach. Population \& Societies, $400 \mathrm{http}: / / \mathrm{www}$. ined.fr/en/publications/pop_soc/bdd/publication/540/.

Toulemon, L. (2006). Fertility among immigrant women in France: new data, a new approach. Prepared for Population Association of America 2006 annual meeting, Los Angeles, California, March 30-April 1, 2006.

Toulemon, L., \& Mazuy, M. (2004). Comment prendre en compte l'âge à l'arrivée et la durée de séjour en France dans la mesure de la fécondité des immigrants? INED. http://www.ined.fr/fichier/t publication/1053/publi_pdf1_120.pdf. Accessed 23 October 2013.

Tromans, N., Natamba, E., \& Jefferies, J. (2007). Have women born outside the UK driven the rise in UK births since 2001? Population Trends, 136, 28-42.

Tufte, E. R. (2001). The visual display of quantitative information (2nd ed.). Graphics Press USA.

Tønnessen, M. (2019). Declined total fertility rate among immigrants and the role of newly arrived women in Norway. European Journal of Population/Revue européenne de Démographie. https://doi.org/10.1007 /s10680-019-09541-0.

United Nations (2019). World Population Prospects 2019, Age Specific Fertility Rates (ASFR). Downloaded 2. July 2019 from https://population.un.org/wpp/Download/Standard/Fertility/

Van Landschoot, L., Van Bavel, J., \& De Valk, H. (2014). Estimating the contribution of mothers of foreign origin to total fertility: the recent recovery of period fertility in the Belgian region of Flanders. Demographic Research, 30(12), 361-376.

White, M. J., Moreno, L., \& Guo, S. (1995). The interrelation of fertility and geographic mobility in Peru: a hazards model analysis. International Migration Review, 29(2), 492-514. https://doi.org/10.2307 12546791 .

Wilson, B. (2019). Understanding how immigrant fertility differentials vary over the reproductive life course. European Journal of Population. https://doi.org/10.1007/s10680-019-09536-x.

Wolf, K. (2016). Marriage migration versus family reunification: how does the marriage and migration history affect the timing of first and second childbirth among Turkish immigrants in Germany? European Journal of Population, 32(5), 731-759. https://doi.org/10.1007/s10680-016-9402-4.

Young, C. M. (1991). Changes in the demographic behaviour of migrants in Australia and the transition between generations. Population Studies, 45(1), 67-89.

Yusuf, F., \& Rockett, I. (1981). Immigrant fertility patterns and differentials in Australia, 1971-1976. Population Studies, 35(3), 413-424. https://doi.org/10.2307/2174663.

Zumpe, J., Dormon, O., \& Jefferies, J. (2012). Childbearing among UK born and non-UK born women living in the UK. ONS. http://www.ons.gov.uk/ons/dcp171766_283876.pdf. Accessed 25 October 2012.

Publisher's Note Springer Nature remains neutral with regard to jurisdictional claims in published maps and institutional affiliations. 